\title{
Automatic Evaluation of Teacher-Student Interaction Based on Dialogue Text
}

\author{
Jiao Lu ${ }^{1, a}$, Dan Wang ${ }^{1, b}$, Zuying Luo ${ }^{2, c, *}$ \\ ${ }^{1}$ College of Information Science and Technology, Beijing Normal University, Beijing, China \\ ${ }^{2}$ Research Center of Virtual Reality and Visualization Technology and Engineering, Beijing Normal \\ University, Beijing 100875, China \\ a201521210003@mail.bnu.edu.cn,b201521210005@mail.bnu.edu.cn, ${ }^{\mathrm{c}}$ luozy@bnu.edu.cn \\ *corresponding author
}

Keywords: classroom observation, teacher-student interaction, text analysis, classroomteaching automatic evaluation.

\begin{abstract}
Quantitative evaluation in class can effectively improve the quality of classroom teaching, but the automatic evaluation tool is very scarce. In order to be able to carry out large-scale automatic evaluation of teacher-student interaction, this paper first designed a set of indicator system for the classroom interactive evaluation; and then input teacher and student dialogue text from the classroom teaching video; and asked two education evaluation professionals to evaluate the interaction between teachers and students on the same lesson according to the video and text respectively to observe the validity of the interactive evaluation of teachers and students based on the dialogue text. This paper then presented a teacher-student interactive automatic coding technique (SAC) based on dialogue sentences, and constructed a set of classroom-teaching automatic evaluation system (BIAS) for teacher-student interaction. The experimental results show that BIAS not only provides more interactive evaluation function of teachers and students, but also improves the educational evaluation personnel's coding efficiency by 7.3 times compared with the Flanders coding system (FIAS), which is manually coded.
\end{abstract}

\section{Introduction}

In terms of the large number of evaluation indicators in the classroom teaching process and the need to use a number of teachers and professionals to cooperate in the team-type classroom observation method [1], those indicator's workload is very large and difficult to carry out largescale normal classroom evaluation. Therefore, the use of information technology for teacher-student automatic analysis and evaluation is the key to carry out large-scale normal classroom evaluation of the basic education.

Therefore, in the field of classroom teaching evaluation, the contribution of this work is as follows:(1) Through the comparison experiment, we can draw the conclusion that the teacher and student dialogue text can effectively evaluate the interaction between teachers and students according to the classroom teaching;(2) Based on the text of teacher-student dialogue in classroom teaching, an teacher-student interactive automatic coding technique (SAC) based on dialogue sentences is proposed;(3) A set of classroom teaching automatic evaluation system (BIAS) for teacher-student interaction is constructed. BIAS can liberate the educational evaluation experts from the heavy manual coding work, and solve the problem of lack of effective quantitative evaluation 
tools for large-scale classroom evaluation.

\section{Research Background}

\subsection{Classroom Evaluation}

At present, the quantitative evaluation of classroom interaction between teachers and students is divided into two categories[2]:

The first category is the use of fixed voting device and handheld mobile smart devices . However,there is no substantive large-scale application of electronic schoolbag based on handheld mobile smart devices in basic education.

The second category is the manual coding technology, represented by Flanders Interaction Analysis Coding (FIAC), which classifies the classroom teacher-student interaction by educational evaluation experts, for example, FIAC is 10 categories [4], iFIAS is 14 categories, ITIAS is 18 categories . However, such manual coding technology is limited by high human costs,

\subsection{Analysis Coding of Teacher-Student Interaction Represent by FIAC}

Currently, the quantitative evaluation method of classroom teaching which is widely recognized and applied in pedagogy is Flanders (FIAC)[3].

Although the Flanders coding system can be used to develop the corresponding coding support tool, its work intensity is too large, which requires 1 time of artificial coding in every 3 seconds, and requires the observer to manually enter 800 to 1000 codes in each class of 40 to 50 minutes. It can not avoid code error due to subjective differences of coder.

\section{The Evaluation System for Teacher - Student Interaction}

This article uses the evaluation scale developed by Ministry of Education Basic Education Quality Testing Center[6], The scale is divided into three dimensions: teacher behavior, teacherstudent interaction, group activity, As shown in Table 1.

Tablel part of SAC coding system

\begin{tabular}{|c|c|c|c|c|}
\hline $\begin{array}{l}\text { First class } \\
\text { behavior }\end{array}$ & $\begin{array}{l}\text { Code for first } \\
\text { class behavior }\end{array}$ & Secondary behavior & $\begin{array}{l}\text { Code for } \\
\text { Secondary } \\
\text { behavior }\end{array}$ & Digital coding \\
\hline \multirow{3}{*}{$\begin{array}{l}\text { Teacher } \\
\text { management }\end{array}$} & \multirow[t]{3}{*}{ TM } & Manage order & TM order & 00 \\
\hline & & Seat adjustment & TM seat & 01 \\
\hline & & Teaching organization & TM organize & 02 \\
\hline \multirow[t]{2}{*}{ Teacher question } & \multirow[t]{2}{*}{ TQ } & Open mind question & TQ open & 10 \\
\hline & & Closed question & TQ closed & 11 \\
\hline \multirow[t]{2}{*}{ Teacher response } & \multirow[t]{2}{*}{ TR } & $\begin{array}{c}\text { Teacher response to students' } \\
\text { questions }\end{array}$ & TR question & 20 \\
\hline & & No response & TR No response & 21 \\
\hline \multirow{6}{*}{ Teacher feedback } & \multirow{6}{*}{ TF } & Positive feedback & $\begin{array}{ll}\text { TF } & \text { Positive } \\
\text { feedback } & \\
\end{array}$ & 30 \\
\hline & & Dependency recognition & $\begin{array}{l}\mathrm{TF} \text { Dependency } \\
\text { recognition }\end{array}$ & 31 \\
\hline & & Timely encouragement & $\begin{array}{l}\text { TF timely } \\
\text { encouragement }\end{array}$ & 32 \\
\hline & & Actively guide & TF guide & 33 \\
\hline & & Interrupt students & TF interrupt & 34 \\
\hline & & Encourage students & TF encourage & 35 \\
\hline
\end{tabular}




\section{Sentence Analysis Code(SAC)}

\subsection{Effectiveness Validation of SAC}

In order to observe the effectiveness of "interactive evaluation of teachers-student based on SAC", we invited two class instruction professionals to manually encode 107 interactive textbooks for a 42-minute classroom video, one of which was based only on teacher-student interactive text , while others was based on video and text.

The cumulative error time is 28.5 minutes $(67.9 \%$ of the 42 -minute video) compared to the exact result of the slow coding based on the video and text, and the ambiguity is 9.2 minutes $21.9 \%$ ), and the error code was 4.3 minutes $(10.2 \%)$. In the 107 sentences of teacher-students interaction, correctly encoded 97 sentences (including the code is completely correct and ambiguity), there are ten wrong code, the coding accuracy is $90.7 \%$, which indicates : teacher-student dialogue text covers the vast majority of teachers and students interactive information, so we can make a quick and effective evaluation based on the text of the class.

\subsection{SAC Secondary Serial Coding of SAC Based on Rule and Dictionary}

SAC automatic coding uses a rule and dictionary method composed of two levels of text categorization encoder, that is, the first use of the rules of classifier for a class of coding, and then use the dictionary classifier for two-level behavior refinement coding .

Each category template can be composed of multiple rules, the rules support the logical operation of the field information, logical operation order .

\subsection{Examples of SAC}

Based on text processing technology, we propose SAC automatic coding technology based on teacher-student dialogue text. In order to illustrate the working principle of SAC, we intercepted a class of video from 8 minutes to 9 minutes, SAC coding, 1 minutes video encoding a total of 10, the specific encoding results shown in Table 2.

Table 2 Examples of SAC automatic coding and manual correction in BIAS systems

\begin{tabular}{|c|c|c|c|c|c|c|}
\hline & \multirow[t]{2}{*}{ Teacher - student dialogue } & \multicolumn{2}{|c|}{ Text time } & \multirow{2}{*}{$\begin{array}{c}\text { SAC Automatic } \\
\text { coding }\end{array}$} & \multirow{2}{*}{$\begin{array}{l}\text { Manual } \\
\text { correction }\end{array}$} & \multirow{2}{*}{$\begin{array}{l}\text { Encoding } \\
\text { result }\end{array}$} \\
\hline & & Start time & End Time & & & \\
\hline 1 & $\begin{array}{l}\text { Teacher: just through the video we can } \\
\text { understand so many problems, can be used } \\
\text { as a research topic. }\end{array}$ & $0: 08: 19.74$ & $0: 08: 25.70$ & 【TT explain】 & $\begin{array}{l}\text { 【 TT } \\
\text { transfer】 }\end{array}$ & 52 \\
\hline 2 & $\begin{array}{l}\text { Teacher: In fact, we can, for example, the } \\
\text { difference between the north and south } \\
\text { gardens, we have been to Beijing Park, there } \\
\text { are no students to Suzhou Park, Jinan Park? }\end{array}$ & $0: 08: 27.00$ & $0: 08: 36.76$ & 【TQ closed 】 & & 10 \\
\hline 3 & Student: We've been & $0: 08: 36.98$ & $0: 08: 37.54$ & 【TL answer】 & & 42 \\
\hline 4 & $\begin{array}{l}\text { Teacher: Do you find that his architectural } \\
\text { style is very different? }\end{array}$ & $0: 08: 37.54$ & $0: 08: 42.10$ & 【TQ closed 】 & & 10 \\
\hline
\end{tabular}

\section{BNU Interactive Analysis System (BIAS)}

In order to evaluate the effect of classroom teaching quickly and accurately, this paper develops a set of classroom teaching automatic evaluation system (BIAS) based on SAC method. Its working principle and system architecture are shown in Figure 1. Combined with a BIAS application 


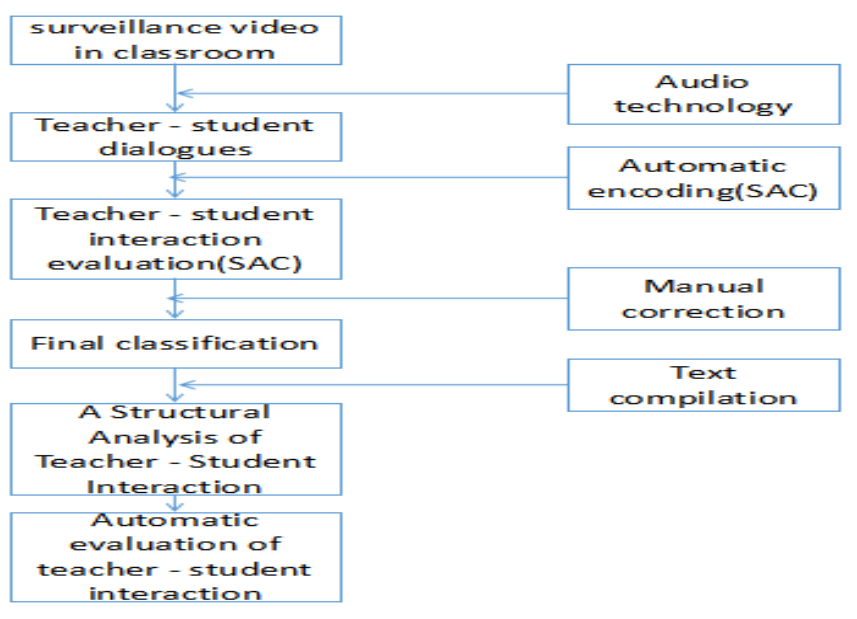

Figure 1 Working block diagram of BIAS

Acquisition of conversational text based on the voice input technology; The annotation information is obtained by the SAC method; According to the teacher and student dialogue text information, classroom evaluation professionals SAC text annotation information for artificial annotation modification, mainly for coding errors or ambiguity of the SAC annotation for manual correction. Based on the teacher-student interaction evaluation data, the classroom teaching effect is automatically evaluated.

\section{The Application of BIAS}

It is similar to FIAS that BIAS can evaluate the class performance automatically based on the structured data. The number of SAC codes is 35, which is much more than that of FIAC[5], giving BIAS based on SAC codes a lot of more ways in the application of class auto-evaluation. In the following, the author would make some expression of BIAS based on the data including $i$ 、 $t b(i)$ 、 te(i) and N(i); Also, there will be a kind of analysis of a 42-minute-long class-teaching video.

\subsection{The Analysis of Auto-Classification In Teaching Behavior}

- The analysis of Frequency and accumulated time of the second-ranked teaching behavior

We can find out the coefficient $c_{p}$, j(i) as follows:

$c_{p, j}(i)=\left\{\begin{array}{l}1 \text { as } N(i)=N_{p, j} \\ 0 \text { others }\end{array}\right.$

In the above formula, if the $\mathrm{i}$-th sentence belongs to the secondary behavior $\mathrm{j}$ in the first behavior P, $c_{p, j}(i)=1$, others $c_{p, j}(i)=0$.

Meanwhile, we can get the accumulated time of the secondary behavior in a single class $t_{p, j}$ :

$$
t_{p, j}=\sum_{i=1}^{S A}\left\{c_{p, j}(i)[t e(i)-t b(i)]\right\}
$$

In the above formula, $t b(i)$ is the start time of a sentence, and te(i) is the cut-off time

- The analysis of frequency and accumulated time of the first-ranked teaching behavior

In a single class, we can get the frequency and the accumulated time of the first-ranked teaching behavior based on the analysis of the secondary behavior above. And the function is as below:

$$
F_{p}=\sum_{j=0}^{S p} F_{p, j}
$$




$$
t_{p}=\sum_{j=0}^{S p} t_{p, j}
$$

In which $S p$ is the total numbers of the second-ranked teaching behavior.

- The visualization of the teaching-behavior analysis

The distribution proportion of the first-ranked teaching behavior is the ratio that each kind of behavior occupying the total class time. And the chart is as follows:

In fact, we can analyses each kind of second-ranked teaching behavior based on its first-ranked teaching behavior, such as the analysis of TQ showing in figure 3 .

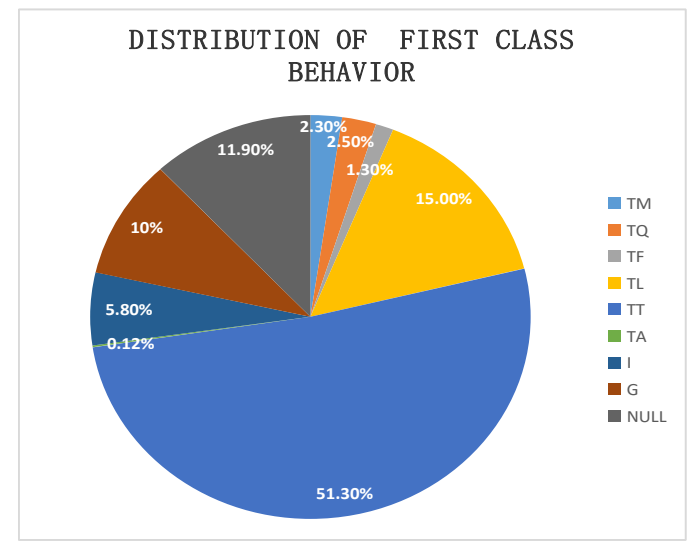

Figure 2 distribution of first class behavior

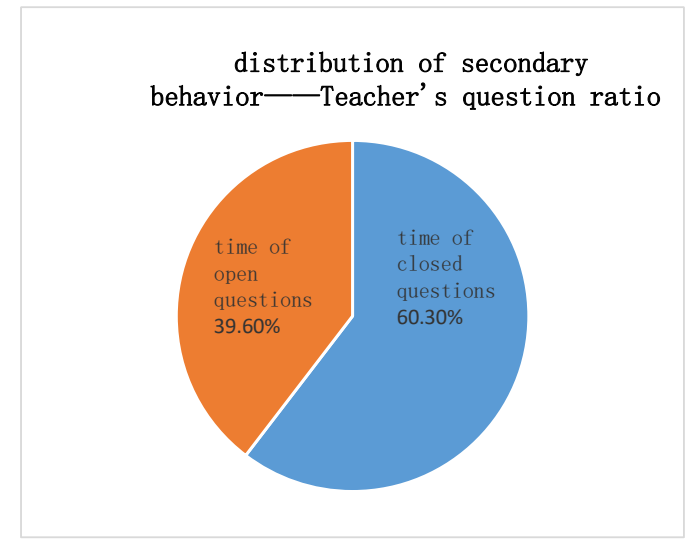

Figure 3 distribution of secondary behavior

\subsection{The Auto-Analysis of Interaction Between Teacher-Student}

Based on the FIAS, we can analyses $R_{t s} 、 R_{s s} 、 R_{q c}$ and $R_{t q}$ automatically .In the 42-minute-long class mentioned above, the total time of the teacher' s speaking is 24 minutes and 13 seconds, and the total time of the students' speaking is 6 minutes and 6 seconds, in comparison with the time of silence and chaos(including interactions and activities) being 6 minutes and 27 seconds. Therefore, $R_{t s}=57.7, R_{s s}=14.5, R_{q c}=15.4$.

\subsection{The new indicators of BIAS Auto-Analysis system}

Despite auto-classification and auto-analysis for FIAS,BIAS can do a lot more such as autoclassification of opening and closed questions.

During the class, the teacher asked 16 questions totally, of which the number of opening ones is 12 and that of closed ones is 4 .In another word, the percentage of opening ones is $75 \%$, while the same ratio of closed ones is $25 \%$.

\section{Conclusions}

In order to test the efficiency of BIAS when it is used to measure the interaction, we choose 5 surveillance videos of classes from the Primary School Affiliated to Beijing Normal University. The results are shown in the following chart. And the length of them is 43、42、37、40 and 42 minutes.

The experimental results show that: the average coding accuracy rate of BIAS system is $79.28 \%$ :

And education evaluation efficiency are increased by $(816-98.2) \div 98.2=7.3$ times. 
Table 3 coding efficiency of BIAS

\begin{tabular}{|c|c|c|c|c|c|c|c|}
\hline \multirow{2}{*}{ case } & \multirow{2}{*}{$\begin{array}{l}\text { video } \\
\text { time }\end{array}$} & \multirow{2}{*}{$\begin{array}{l}\text { Number of } \\
\text { sentences }\end{array}$} & \multicolumn{2}{|c|}{ Number of codes } & \multirow{2}{*}{$\begin{array}{l}\text { Coding } \\
\text { ratio }\end{array}$} & \multirow{2}{*}{$\begin{array}{c}\text { Number of } \\
\text { correctio } \\
\text { ns }\end{array}$} & \multirow{2}{*}{$\begin{array}{c}\text { Coding } \\
\text { accuracy }\end{array}$} \\
\hline & & & FIAS & SAC & & & \\
\hline 1 & $43: 00$. & 639 & 860 & 639 & $74.30 \%$ & 1112 & $82.50 \%$ \\
\hline 2 & $42: 00$. & 392 & 840 & 392 & $46.70 \%$ & 108 & $72.40 \%$ \\
\hline 3 & $37: 16$. & 549 & 740 & 549 & $74.20 \%$ & 126 & $77.00 \%$ \\
\hline 4 & $40: 05$. & 442 & 800 & 442 & $55.30 \%$ & 95 & $78.50 \%$ \\
\hline 5 & $42: 00$. & 356 & 840 & 356 & $42.40 \%$ & 50 & $86.00 \%$ \\
\hline average & $40: 52$ & 475.60 & 816.00 & 475.60 & $58.58 \%$ & 98.20 & $79.28 \%$ \\
\hline
\end{tabular}

\section{Acknowledgements}

This paper is supported by NSFC project (61274033).

\section{References}

[1] Yang Tao, Xin Tao, Dong Qi, French basic education quality evaluation system analysis, comparative education research, 2013(4): 60-64

[2] Lu Litao, Liang Wei, Shen Qian, China's classroom teaching evaluation of the status quo reflection and improvement path, China Education Journal, 2012,06: 43-47

[3] Evans T P. Flanders System of Interaction Analysis and Science Teacher Effectiveness.[J]. Instruction, 1970:23.

[4] GU Xiao-qing, WANG Wei.New exploration of classroom analysis techniques to support teachers' professional development [J]. China Electrotechnical Education,2004, (7): 19-21.

[5] FANG Hai-guang, GAO Cheng-zhu, CHEN Jia.Improved Flanders Interactive Analysis System and Its Application [J]. China Electrotechnical Education, 2012, (10): 109-113

[6] Jang H, Kim E J, Reeve J. Longitudinal test of self-determination theory's motivation mediation model in a naturally occurring classroom context[J]. Journal of Educational Psychology, 2012, 104(4): 1175. 